\title{
Gasoline prices and traffic safety in Mississippi
}

\author{
Guangqing Chi ${ }^{\mathrm{a}, *}$, Arthur G. Cosby ${ }^{\mathrm{b}, 1}$, Mohammed A. Quddus ${ }^{\mathrm{c}, 2}$, Paul A. Gilbert ${ }^{\mathrm{d}, 3}$, David Levinson ${ }^{\mathrm{e}, 4}$ \\ a Department of Sociology and Social Science Research Center, Mississippi State University, PO Box C, Mississippi State, MS 39762, USA \\ b Social Science Research Center, Mississippi State University, PO Box 5287, Mississippi State, MS 39762, USA

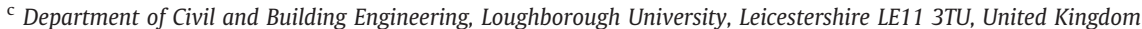 \\ d Department of Sociology, Mississippi State University, PO Box C, Mississippi State, MS 39762, USA \\ e Department of Civil Engineering, University of Minnesota, 500 Pillsbury Drive SE, Minneapolis, MN 55455, USA
}

\section{A R T I C L E I N F O}

\section{Article history:}

Received 9 February 2010

Received in revised form 19 September 2010

Accepted 20 October 2010

Available online 9 November 2010

\section{Keywords:}

Gasoline prices

Traffic crashes

Traffic safety

Age

Gender

Race

\begin{abstract}
A B S T R A C T
Problem: Limited literature suggests that gasoline prices have substantial effects on reducing fatal crashes. However, the literature focuses only on fatal crashes and does not examine the effects on all traffic crashes. Methods: Mississippi traffic crash data from April 2004-December 2008 from the Mississippi Highway Patrol and regular-grade unleaded gasoline price data from the Energy Information Administration of the U.S. Department of Energy were used to investigate the effects of gasoline prices on traffic safety by age, gender, and race. Results: Gasoline prices have both short-term and intermediate-term effects on reducing total traffic crashes and crashes of females, whites, and blacks. The intermediate-term effects are generally stronger than the short-term effects. Gasoline prices also have short-term effects on reducing crashes of younger drivers and intermediate-term effects on older drivers and male drivers. Impact on Industry: Higher gasoline taxes reduce traffic crashes and may result in additional societal benefits.
\end{abstract}

(C) 2010 National Safety Council and Elsevier Ltd. All rights reserved.

\section{Introduction}

Between 2000 and 2007, more than 40,000 deaths due to traffic crashes occurred annually in the United States (National Highway Traffic Safety Administration [NHTSA], 2009). In 2008, U.S. roadway deaths fell when gasoline prices reached $\$ 4$ per gallon; there were 37,313 deaths due to vehicle traffic crashes, which is $9.1 \%$ lower than in 2007 and the fewest since 1961. It has been argued that this drop is in part due to the rise in gasoline prices and consequent adjustments of travel behaviors (e.g., Thomas, 2009). In the past, high gasoline prices have had similar correlations with roadway deaths. For example, traffic fatalities fell more than 16\% from 1973 to 1974 when the oil crisis occurred. International oil prices historically have fluctuated frequently (Fig. 1), which could influence traffic safety. ${ }^{5}$

Though a limited number of studies have examined the effects of gasoline prices on traffic safety, they have reported on fatal crashes

\footnotetext{
* Corresponding author. Tel.: +1 662325 7872; fax: +1 6623257966 .

E-mail addresses: gchi@ssrc.msstate.edu (G. Chi), arthur.cosby@ssrc.msstate.edu (A.G. Cosby), m.a.quddus@lboro.ac.uk (M.A. Quddus),pag76@msstate.edu

(P.A. Gilbert), dlevinson@umn.edu (D. Levinson).

${ }^{1}$ Tel.: +1 662325 7127; fax: + 16623257966 .

2 Tel.: + 44150922 8545; fax: +441509223981.

${ }^{3}$ Tel.: +1 769232 3552; fax: +1 6623257966 .

${ }^{4}$ Tel.: +1 612625 6354; fax: +1 6126267750 .

${ }^{5}$ Traffic safety encompasses both decreases and increases in traffic crashes.
}

only (e.g., Grabowski \& Morrisey, 2004, 2006; Leigh \& Geraghty, 2008; Leigh \& Wilkinson, 1991; Wilson, Stimpson, \& Hilsenrath, 2009). While fatalities are the most grave, they represent the smallest proportion of all crashes and thus provide a biased representation of the overall level of traffic safety (Kenkel, 1993; McGwin \& Brown, 1999). This paper extends the research by examining total traffic crashes to more accurately reflect the impact that gasoline prices have on traffic safety. Specifically, we investigate the effects of gasoline prices on total traffic crash rates from April 2004 to December 2008 in Mississippi. We further analyze these effects by age, gender, and race to explore the possible variations of these effects. This paper subsequently is organized into five additional sections. The next section reviews the findings of existing studies. The following section introduces the data and methods used. The results section reports the effects of gasoline prices on the total traffic crash rate as well as the crash rates by age, gender, and race. Finally, this paper discusses the contributions and policy implications, suggests further research directions, and summarizes the findings.

\section{Prior Research}

Existing research typically has examined traffic crashes and fatalities as functions of traffic characteristics, road conditions, climate, and socio-demographic characteristics (Quddus, 2008a). Most studies have failed to consider the effect of gasoline prices in studying traffic safety, and no research has investigated gasoline price 


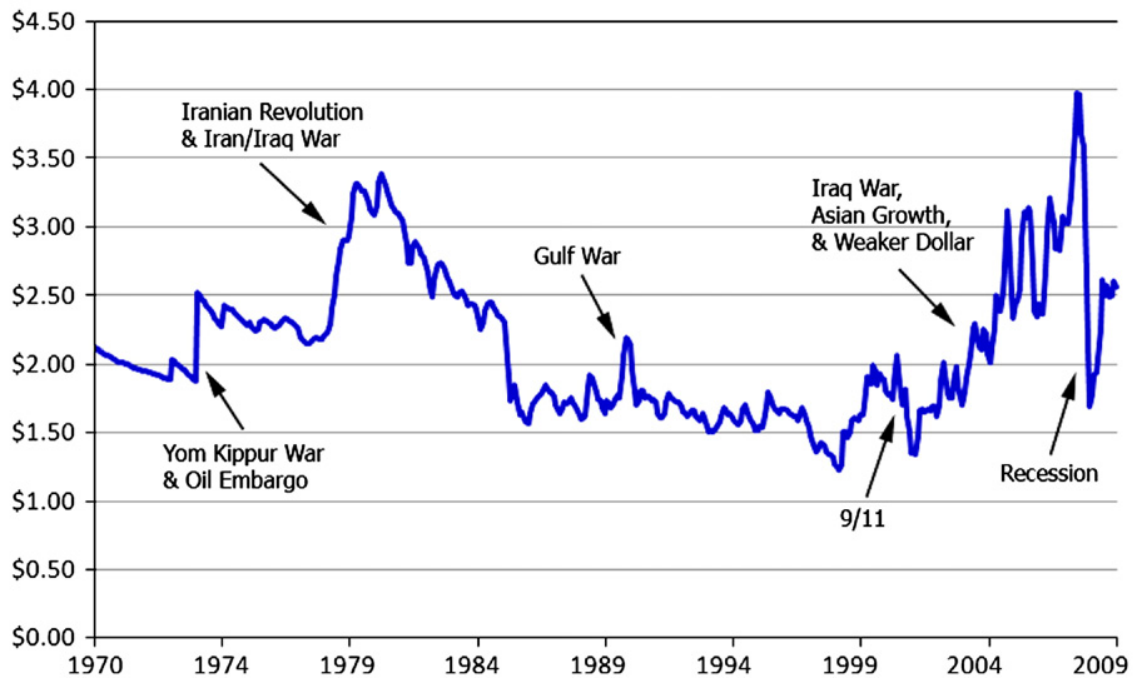

Fig. 1. Average gasoline prices (in January 2009 dollars) in the U.S., 1970-2009. Notes: Price swings have partly resulted from periods of oversupply or shortage, which often are related to episodes of war or crisis in the Middle East and other oil-producing regions (Williams, 2008). Oil prices increased tremendously from 1973-1974. In the late 1970s and into the 1980s, oil prices doubled between 1978 and 1981. Beginning in 1982, the price of oil remained weak until 1990. After the spike in oil prices in 1991, prices decreased until 1998, then surged again until early 2001, then fell in 2002. By 2003, oil prices rose and continued to rise until mid-2008, when prices plummeted into late 2008. Data source: Energy Information Agency, US Department of Energy.

effects on total traffic crashes. However, there exist a limited number of studies that analyze the effect on fatal crashes, and from these we can obtain a preliminary understanding of the effect on traffic safety. These studies found that gasoline price increases reduce traffic fatalities. For example, Leigh and Wilkinson (1991) found that higher gasoline prices lead to fewer traffic fatalities, and Leigh and Geraghty (2008) found that the surge in oil prices in the late 1970's and early 1980 's correlated with a decrease in fatal crashes. From 1972 to 1975 , nominal and real gasoline prices increased $58.7 \%$ and $23.4 \%$, while traffic deaths and the fatality rate decreased by $18.5 \%$ and $20.4 \%$, respectively. From 1979 to 1982, nominal and real gasoline prices increased 46.6\% and $10.2 \%$, while traffic deaths and the fatality rate decreased by $14.4 \%$ and $15.4 \%$, respectively. Grabowski and Morrisey (2004) found that a $10 \%$ increase in gasoline prices reduces traffic fatalities by $3.4 \%$ over a twoyear period and by more than twice that figure for younger drivers. Furthermore, they argue that a significant cause of the stability of traffic fatality rates throughout the 1990's was low gasoline prices. They estimate that if gasoline prices had remained constant at a high of \$2.13 (in 2002 dollars) from 1985 to 2000, then over 92,000 fewer traffic fatalities would have occurred in that period. Grabowski and Morrisey (2006) conceptualized the price of gasoline as an exogenous variable and found that increasing state gasoline taxes by $10 \%$ caused a $0.6 \%$ decrease in fatalities per capita or per vehicle mile traveled (VMT).

Some of these studies have also differentiated the effect of gasoline prices on fatal crashes by age. The cohort that has the highest crash rate is younger drivers under age 24 , whose crash rates have been attributed to immaturity and driving inexperience, poor risk perception, excessive risk-taking, poor vehicle handling skills, and more nighttime driving (e.g., Arnett, 2002; Edwards, 2001; Williams, 2003; Williams, Preusser, \& Ferguson, 1998). Leigh and Wilkinson (1991) found that a state with one percentage point more younger drivers than a bordering state will have a fatality rate more than $8 \%$ higher. Grabowski and Morrisey (2004) found that gasoline price increases have a higher impact on younger drivers than older drivers: with a $10 \%$ reduction in gasoline prices, the fatality rate increased $6.6 \%$ for drivers 18 to 20 years old but $5.8 \%$ for drivers 21 to 24 years old. However, these prior studies did not examine gender and race variations of gasoline price effects on traffic safety. A large body of research has found variations of traffic safety by gender and race (e.g., Hilton, 2006; Mayhew, Ferguson, Desmond, \& Simpson, 2003); gasoline price effects on traffic safety may also differ by gender and race. By exploring the possible variations of these effects, this study adds to the knowledge of how gasoline prices affect traffic safety.

Gasoline prices influence traffic safety possibly through three intermediate factors: trip frequency and distance, commute modes, and driving behaviors. First, rising gasoline prices could cause people to drive shorter distances by reducing trip frequency and distance as well as making more multi-purpose (linked or chained) trips rather than single-purpose trips. Second, an increase in gasoline prices could cause some drivers to switch from personal vehicle usage to other commuting modes, such as using public transportation, carpooling, biking, or walking. Third, surging gasoline prices could cause people to drive in a more fuel-efficient manner, such as driving more slowly and reducing sudden speeding and braking, which in turn likely lowers crash risk. ${ }^{6}$ The effects of gasoline prices on the three intermediate factors eventually lower the probability of traffic crashes and lead to greater traffic safety. Thus, we expect that as gasoline prices increase, traffic crash rates will decrease. ${ }^{7}$

\section{Data and Methods}

\subsection{Data and variables}

Most studies that analyze gasoline price effects on traffic safety (e.g., Grabowski \& Morrisey, 2004; Leigh \& Wilkinson, 1991; Wilson

\footnotetext{
${ }^{6}$ The three possible paths through which gasoline prices affect traffic safety likely occur immediately after gasoline price increases. However, over the long term, gasoline prices may influence traffic safety through two additional factors-residential relocation and higher vehicle fuel efficiency. Increased gasoline prices could induce workers, especially low- and medium-income automobile commuters who live far from their workplaces, to relocate closer to their workplaces. An increase in gasoline prices could also persuade some drivers to switch to fuel-efficient vehicles, which are generally lighter (and therefore more vulnerable if hit by a larger vehicle but likely to cause less damage to another vehicle or a pedestrian in a crash) but are equipped with better safety technologies (the net effects of lightness and safety have been found to be insignificant; Leigh \& Wilkinson, 1991).

7 These possible links have not been tested in existing studies; this study likewise does not attempt to test these links. Measurement of the intermediate links might have potentially large errors, and the links might be imprecise. Moreover, the data for studying these links are unavailable and may be difficult to collect. Therefore, instead of modeling the effects by these links, this research directly models the effects of gasoline prices on reducing traffic crashes.
} 
Table 1

Descriptive statistics of the variables.

\begin{tabular}{|c|c|c|c|c|c|}
\hline Variables & Observations & Mean & Standard deviation & Minimum & Maximum \\
\hline Monthly crashes - Total & 57 & 11,051 & 1,485 & 8,272 & 14,783 \\
\hline Monthly crashes - Younger (15-23 years) & 57 & 2,938 & 483 & 1,820 & 4,024 \\
\hline Monthly crashes - Older ( $24+$ years) & 57 & 8,115 & 1,120 & 5,865 & 10,960 \\
\hline Monthly crashes - Male & 57 & 6,149 & 830 & 4,668 & 8,406 \\
\hline Monthly crashes - Female & 57 & 4,903 & 670 & 3,515 & 6,443 \\
\hline Monthly crashes - White & 57 & 6,738 & 927 & 4,977 & 9,221 \\
\hline Monthly crashes - Black & 57 & 3,583 & 496 & 2,689 & 4,763 \\
\hline Monthly crashes - Latino & 57 & 595 & 165 & 327 & 984 \\
\hline Monthly VMT (in millions) & 57 & 3,342 & 217 & 2,921 & 3,730 \\
\hline Gasoline price (U.S. dollars per gallon) & 57 & 2.60 & 0.52 & 1.61 & 3.82 \\
\hline Seat belt use (percent) & 57 & 65.58 & 4.21 & 61.30 & 71.70 \\
\hline State unemployment (percent) & 57 & 6.87 & 0.85 & 5.70 & 10.40 \\
\hline Alcohol consumption (gallons per capita) & 57 & 27.22 & 0.42 & 26.50 & 27.64 \\
\hline
\end{tabular}

et al., 2009) are based on Fatal Accident Reporting System (FARS) data, which consider only fatal crashes (Voas, Romano, \& Peck, 2009). This study analyzes the effects of gasoline prices on all traffic crashes, including fatal crashes, injury crashes, and property-damage-only crashes with property losses of $\$ 500$ or more. Property-damage-only crashes with property losses less than $\$ 500$ are not included, but all fatal and injury crashes are reported. The data used in this study are Mississippi traffic crash data from April 2004 to December 2008 provided by the Mississippi Highway Patrol and include drivers license service data and electronic crash report data. The data contain detailed information on vehicles, drivers, and passengers involved in traffic crashes as well as the types of traffic crashes. The crash data are reported by $98 \%$ of the law enforcement agencies in Mississippi and include the majority of crashes (personal communication with Captain Randy Ginn, Mississippi Highway Patrol, on June 21, 2010). We also obtained VMT data from the Mississippi Department of Transportation for calculating crash rates. In order to examine whether the relationship between traffic crash rates and gasoline prices varies by age, gender, and race, traffic crashes are disaggregated into seven groups based on the driver who causes the crash: younger drivers (15-23 years old), older drivers ( $24+$ years old), male drivers, female drivers, white drivers, black drivers, and Latino drivers. The summary statistics of the variables are presented in Table 1 .

Regular-grade unleaded gasoline price data were obtained from the Energy Information Administration (EIA) of the U.S. Department of Energy for the period 1970 to 2009. The EIA does not collect gasoline price information specifically for Mississippi but provides average prices for all Gulf Coast states. This study, therefore, applies average prices for the Gulf Coast states to approximate the prices in Mississippi. Gasoline price data are adjusted for inflation (in January 2009 dollars); the adjusted gasoline prices are used as the explanatory variables. Existing studies suggest that the short-term and long-term effects of gasoline prices on reducing traffic crashes may be different (Dahl \& Sterner, 1991; Grabowski \& Morrisey, 2004). The gasoline price threshold, however, is ambiguous. In this study, we follow the Grabowski and Morrisey (2004) study to measure gasoline prices at the current time, a 1-year lag, a 2-year lag, a 3-year lag, and a 4-year lag. The first measure represents short-term effects, the second one represents intermediateterm effects, and the latter three represent long-term effects.

This study also controls for other factors that may affect traffic crashes. First, the seat belt usage rate is used as a control variable, as it has been shown to reduce traffic fatalities. When measuring seat belt usage, previous studies have used the implementation of seat belt laws and treated it as a dummy variable (e.g., Grabowski \& Morrisey, 2004). However, drivers may react to safety regulations by increasing other risky driving behaviors, as discussed in the risk compensation research (e.g., Adams, 1995) and the Peltzman (2004) effect. Thus, the seat belt usage rate is a better measure than the implementation of seat belt laws. Seat belt usage data were provided by the Social Science Research Center of Mississippi State University, who had prepared it for the Mississippi Department of Public Safety. However, the data were available only at the annual level.

Second, alcohol consumption is used as a control variable. Risk assessment and safe driving capabilities are impaired by alcohol consumption (Leigh \& Wilkinson, 1991). Some studies argue that the implementation of drinking-and-driving laws can reduce traffic fatalities and treat such implementation as a dummy variable (e.g., Grabowski \& Morrisey, 2004). This study uses the annual alcohol consumption amount in gallons per capita, which provides more detailed information for measuring the effects that alcohol consumption has on traffic safety. The data came from the Beer Institute (2009). However, the data were available only at the annual level.

Third, unemployment rate is also used as a control variable because economic conditions affect an individual's capability to consume gasoline and have therefore been found to affect traffic crashes (Graham \& Glaister, 2003; Leigh \& Wilkinson, 1991; Quddus, 2008a). Areas with high unemployment rates are more vulnerable to rising gasoline prices. ${ }^{8}$ Monthly unemployment data were obtained from the U.S. Bureau of Labor Statistics (2009).

Other variables, such as driving behaviors, travel speeds, characteristics of the vehicle fleet, and administrative driver's suspension, are argued to affect traffic safety (Leigh \& Geraghty, 2008). However, this study is conducted at the aggregated level, at which these factors have much less variation than at the individual level, and thus they presumably have much less explanatory effect on traffic safety. These factors are not considered in this study.

\subsection{Methods}

The primary objective of this study is to investigate the impact of gasoline prices on traffic crashes while controlling for other contributory factors. This can be achieved by developing appropriate crash prediction models. This study identifies appropriate models based on the data availability and other relevant issues that are addressed below.

The Poisson regression model is often employed as the first choice because the data relating to traffic crashes are random, discrete, and non-negative events (Kulmala, 1995; Miaou, 1994). One of its assumptions is that the mean of crashes equals the variance of

\footnotetext{
${ }^{8}$ Some studies suggest that higher gasoline prices lead to higher unemployment rates (e.g., Carruth, Hooker, \& Oswald, 1998). Thus, unemployment rate and gasoline price variables could be highly correlated, which may generate the multicollinearity problem in the regression analysis. Our Pearson's correlation matrix between unemployment rate and gasoline prices shows that all correlations are below 0.3 . Therefore, the multicollinearity problem is not a concern in this study.
} 
crashes. If this assumption is violated, Poisson-gamma (or negative binomial) regression models are used (Abdel-Aty \& Radwan, 2000; Lord, 2000). A Poisson-gamma regression model can be written as:

$$
\begin{aligned}
& Y_{t} \sim \operatorname{Poisson}\left(\mu_{t}\right) \\
& \log \left(\mu_{t}\right)=\log \left(E_{t}\right)+\beta_{0}+\sum_{j=1}^{k} \beta_{j} X_{j t}+\gamma_{t}
\end{aligned}
$$

where

$Y_{t}$ refers to the observed monthly crash count;

$\mu_{t}$ refers to the expected monthly crash count;

$X_{t}$ refers to the explanatory variables and $k$ is the number of explanatory variables;

$E_{t}$ refers to the crash exposure variable, such as VMT;

$\gamma_{t}$ is a random term that captures unobserved effect over time and $\exp \left(\gamma_{t}\right)^{\sim} \operatorname{Gamma}\left(\frac{1}{\alpha}, \alpha\right)$, in which $\alpha$ is the over-dispersion parameter; and

$\beta_{0}$ and $\beta_{j}$ are parameters to be estimated.

Poisson and Poisson-gamma models are more suitable for crosssectional data and require that the data are not serially correlated (Quddus, 2008b). Our monthly traffic crash data are time-series counts and, therefore, may be serially correlated.

Time series models for continuous data are well developed. The most traditional ones are the Box-Jenkins Autoregressive Integrated Moving Average (ARIMA) models and its various extensions, such as seasonal ARIMA (SARIMA) models. Integer-Valued Autoregressive (INAR) Poisson regression models, which have been developed more recently, are particularly applicable to time series count data analysis, as these models hold the properties of Poisson regression and can deal with serial correlation (Karlis, 2006; Quddus, 2008b). The INAR Poisson model and the Poisson-gamma model usually yield similar results if the data are not serially correlated and the mean of the counts is relatively high (Karlis, 2006; Quddus, 2008b). ${ }^{9}$

Alternatively, the Prais-Winsten regression model (Prais \& Winsten, 1954) can be used to model crash rates as a continuous dependent variable. The Prais-Winsten regression model controls for serial correlation in disturbances by transforming the original series. This model with $\operatorname{AR}(1)$ can be written as:

$\frac{Y_{t}}{V M T_{t}}=\beta_{0}+\sum_{j=1}^{k} \beta_{j} X_{j t}+\mu_{t}$

$\mu_{t}=\rho u_{t-1}+e_{t}$

where

$\rho$ refers to the autocorrelation coefficient for the first-order autoregressive error term, in which a value of 1 suggests there is a perfect autocorrelation (i.e., random walk) among the residuals; and

$e_{t}$ refers to the independently and identically distributed error term with zero-mean and constant variance.

The Prais-Winsten regression model shown in Eq. (2) can be estimated by the Prais-Winsten estimator that is a generalized least squares (GLS) estimator. Once a model is estimated using time-series data, the Durbin-Watson statistic (also known as the $d$-statistic) can be calculated for diagnosing whether the residuals are serially correlated (Durbin \& Winsten, 1950, 1951). If the $d$-statistic is close

\footnotetext{
9 The exploratory analysis indicates that the means of the monthly traffic crashes for our data are quite high (ranging from 595 to 11,051, as shown in Table 1) and that the monthly crash counts are not serially correlated. Thus, the Poisson-gamma regression model can be selected for our study to examine gasoline price effects on traffic crashes.
}

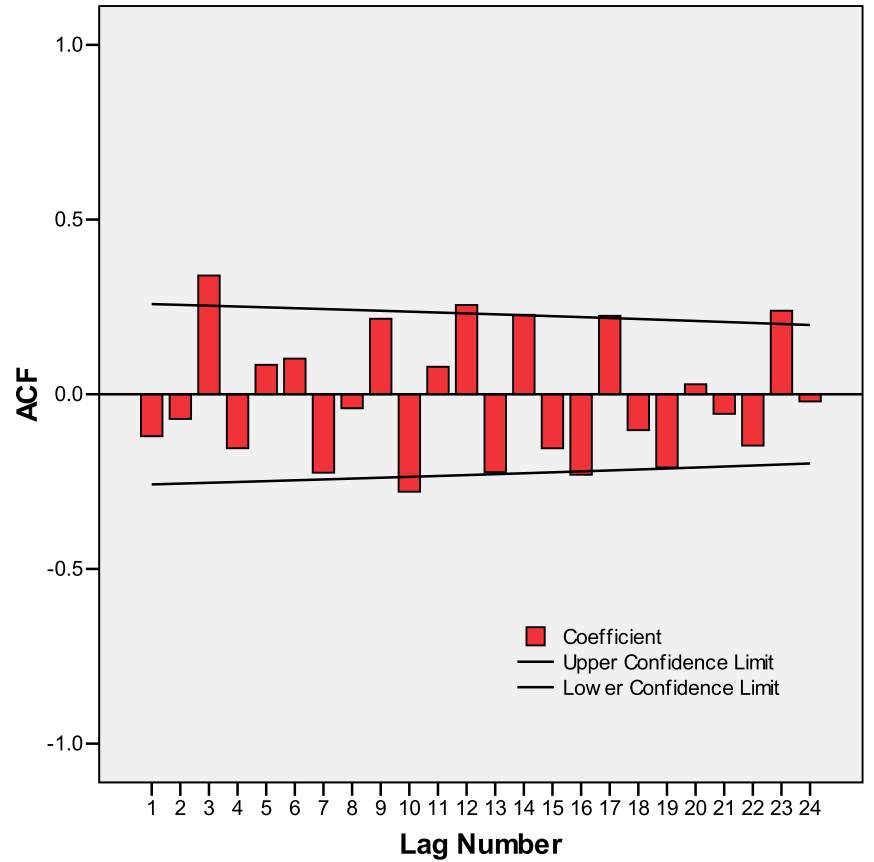

Fig. 2. Autocorrelation function (ACF) for the monthly traffic crashes in Mississippi, 2004-2008

to 2 , it can be assumed that the disturbances are not serially correlated.

\section{Results}

The augmented Dickey-Fuller test (Dickey \& Fuller, 1979) was first employed to diagnose whether monthly crash data are serially correlated. The results suggest that neither monthly traffic crashes nor crash rates are serially correlated. In addition, the plot of autocorrelation function for total monthly crashes does not indicate any systematic pattern (Fig. 2). Thus, Poisson-gamma regression models are used to develop crash prediction models ${ }^{10}$ for our data. Since monthly VMT is used as an exposure variable, the model actually examines the effect of gasoline prices on crash rates rather than on crash counts. A total of eight different models were estimated; the results are shown in Table 2. Along with the explanatory variables discussed in Section 3.1., a continuous time trend variable is included in all models to control for the effect of time on crash rates.

Another set of crash prediction models were developed using the Prais-Winsten linear regression model with AR(1) error term. The dependent variable, crash rates, was transformed into logarithmic scales so as to be comparable to the Poisson-gamma models (see Eq. (1)). Eight models were estimated; the results are shown in Table 3. The $d$-statistic for each model is reduced after the transformation of the original series and becomes close to 2, suggesting that the disturbances from the Prais-Winsten model are not serially correlated.

It is noteworthy that the results from two different specificationsthe Poisson-gamma and the Prais-Winsten regression modelsprovided similar results in terms of the statistical significance of variables (at the $90 \%$ confidence level) and the magnitudes of the coefficients. This implies that the results are consistent and trustworthy. One exception is the model associated with black drivers, in which

\footnotetext{
${ }^{10}$ ARIMA models were also estimated. However, the best ARIMA model (based on goodness-of-fit statistics) eliminated the primary explanatory variables-gasoline prices-from the models. Therefore, these results are not presented and discussed.
} 


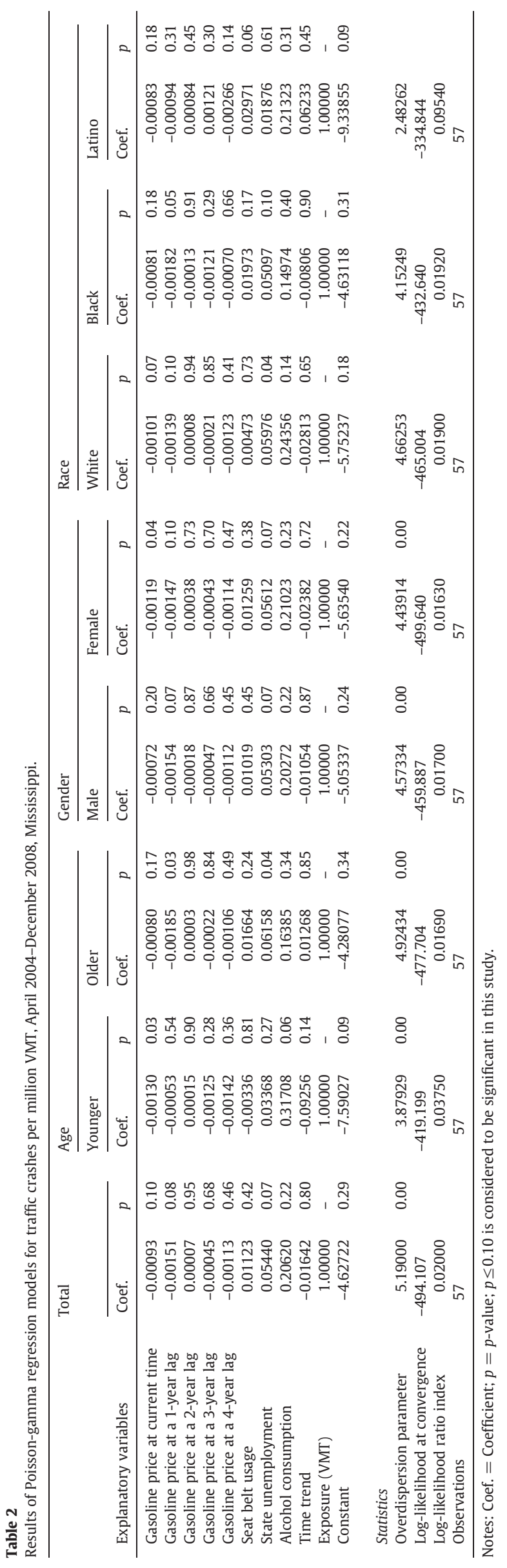

gasoline price at the current time is statistically insignificant in the Poisson-gamma model but becomes marginally significant in the Prais-Winsten regression model. The results from the Prais-Winsten regression models (Table 3 ) are used to interpret the effects of explanatory variables on crash rates.

\subsection{Gasoline prices and total crashes per VMT}

We first illustrate the association between gasoline prices and traffic crash rates. Fig. 3 shows gasoline prices (adjusted for inflation in January 2009 dollars) and traffic crashes per million VMT in Mississippi from April 2004 to December 2008. Both gasoline prices and crash rates are standardized by indices (the first week of April $2004=100$ ) to better visualize the association between their corresponding lines. Fig. 3 clearly indicates a negative relationship between gasoline prices and traffic crash rates: when gasoline prices increase, traffic crashes per million VMT decrease; when gasoline prices decrease, traffic crashes per million VMT increase. This pattern can be observed especially in the periods of March-October 2006, January-August 2007, and March-December 2008.

The results from the Prais-Winsten AR(1) regression models support the above observation (Table 3 ). To facilitate the interpretation, the elasticities of crash rates with respect to gasoline price are calculated (Table 4). The elasticities are measured at the studied period's mean price of $\$ 2.60$.

It was found that gasoline price has both short-term and intermediate-term effects on the total crash rate. In the short term, a $1 \%$ increase in the inflation-adjusted gasoline price is associated with a $0.25 \%$ decrease in the monthly total crash rates. Gasoline prices at a 1 -year lag have stronger effects on reducing crashes-a $1 \%$ increase in the inflation-adjusted gasoline price is associated with a $0.47 \%$ decrease in monthly total crashes per million VMT, which is almost twice the short-term effect. Gasoline prices at the 2-year, 3 -year, and 4-year lags are found to have no effects on traffic crashes per million VMT. Thus, the results suggest that gasoline prices have stronger intermediate-term than short-term effects on reducing traffic crash rates but do not have long-term effects.

\subsection{Variations by age}

We examine variations of gasoline price effects on traffic crash rates of younger drivers (15-23 years old) and of older drivers ( $24+$ years old). As shown in Table 4, gasoline price at the current time has effects on reducing the traffic crash rate of younger drivers: a $1 \%$ increase in gasoline prices is associated with a $0.44 \%$ decrease in monthly total crashes per million VMT. Gasoline prices at the 1-year, 2-year, 3-year, and 4-year lags are not found to affect the traffic crash rate of younger drivers. The results also indicate that alcohol consumption and state unemployment increase crashes of younger drivers (Table 3 ).

In contrast, gasoline prices do not affect the crash rate of older drivers in the short term. However, gasoline prices do have a 1-year lag effect on reducing the crash rate of older drivers: a $1 \%$ increase in gasoline prices is associated with a $0.57 \%$ decrease in monthly total crashes per million VMT. The crash rate of older drivers also increases as state unemployment increases.

\subsection{Variations by gender}

We also examine gasoline price effects on traffic crash rates by male and female drivers separately. The results in Table 4 indicate that gasoline prices have an intermediate-term effect on the traffic crash rate of male drivers. A $1 \%$ increase in gasoline prices is associated with a $0.47 \%$ decrease in monthly total crashes per million VMT at a 1-year lag. Similar to the younger and older drivers, the crash rate of male drivers is also affected by state unemployment. As state unemployment increases, crash rate increases. 
Table 3

Results of Prais-Winsten AR(1) regression models for traffic crashes per million VMT, April 2004-December 2008, Mississippi.

\begin{tabular}{|c|c|c|c|c|c|c|c|c|c|c|c|c|c|c|c|c|}
\hline \multirow[b]{3}{*}{ Explanatory variables } & \multirow{2}{*}{\multicolumn{2}{|c|}{ Total }} & \multicolumn{4}{|l|}{ Age } & \multicolumn{4}{|l|}{ Gender } & \multicolumn{6}{|l|}{ Race } \\
\hline & & & \multicolumn{2}{|l|}{ Younger } & \multicolumn{2}{|l|}{ Older } & \multicolumn{2}{|l|}{ Male } & \multicolumn{2}{|l|}{ Female } & \multicolumn{2}{|l|}{ White } & \multicolumn{2}{|l|}{ Black } & \multicolumn{2}{|l|}{ Latino } \\
\hline & Coef. & $p$ & Coef. & $p$ & Coef. & $p$ & Coef. & $p$ & Coef. & $p$ & Coef. & $p$ & Coef. & $p$ & Coef. & $p$ \\
\hline Gasoline price at current time & -0.00094 & 0.05 & -0.00169 & 0.00 & -0.00069 & 0.15 & -0.00075 & 0.11 & -0.00120 & 0.02 & -0.00105 & 0.03 & -0.00088 & 0.07 & -0.00027 & 0.63 \\
\hline Gasoline price at a 1-year lag & -0.00180 & 0.01 & -0.00070 & 0.33 & -0.00218 & 0.00 & -0.00181 & 0.01 & -0.00181 & 0.02 & -0.00169 & 0.02 & -0.00212 & 0.00 & -0.00121 & 0.15 \\
\hline Gasoline price at a 2-year lag & 0.00004 & 0.97 & 0.00067 & 0.48 & -0.00019 & 0.84 & -0.00017 & 0.85 & 0.00028 & 0.78 & 0.00004 & 0.97 & 0.00002 & 0.99 & -0.00054 & 0.63 \\
\hline Gasoline price at a 3-year lag & -0.00038 & 0.64 & 0.00003 & 0.97 & -0.00057 & 0.50 & -0.00037 & 0.64 & -0.00037 & 0.67 & -0.00005 & 0.96 & -0.00101 & 0.23 & 0.00047 & 0.63 \\
\hline Gasoline price at a 4-year lag & -0.00114 & 0.37 & -0.00136 & 0.30 & -0.00108 & 0.41 & -0.00108 & 0.39 & -0.00114 & 0.41 & -0.00129 & 0.32 & -0.00062 & 0.63 & -0.00313 & 0.04 \\
\hline Seat belt usage & 0.00995 & 0.42 & 0.00856 & 0.50 & 0.01079 & 0.39 & 0.00997 & 0.40 & 0.00927 & 0.48 & 0.00354 & 0.78 & 0.02033 & 0.11 & 0.01649 & 0.27 \\
\hline State unemployment & 0.05235 & 0.04 & 0.04755 & 0.06 & 0.05464 & 0.03 & 0.05601 & 0.02 & 0.04827 & 0.07 & 0.05413 & 0.03 & 0.05877 & 0.02 & -0.00999 & 0.73 \\
\hline Alcohol consumption & 0.17058 & 0.21 & 0.36928 & 0.01 & 0.10363 & 0.46 & 0.19687 & 0.14 & 0.14663 & 0.31 & 0.19030 & 0.17 & 0.16759 & 0.23 & 0.08448 & 0.60 \\
\hline Time trend & 0.00098 & 0.83 & -0.01112 & 0.02 & 0.00518 & 0.26 & 0.00007 & 0.99 & 0.00208 & 0.67 & 0.00072 & 0.88 & -0.00096 & 0.84 & 0.01392 & 0.01 \\
\hline Constant & -3.57856 & 0.35 & -10.06993 & 0.01 & -2.16372 & 0.58 & -4.90003 & 0.19 & -3.68333 & 0.37 & -4.22974 & 0.28 & -5.20382 & 0.19 & -4.57733 & 0.32 \\
\hline \multicolumn{17}{|l|}{ Statistics } \\
\hline Adjusted $\mathrm{R}^{2}$ & 0.46 & & 0.59 & & 0.44 & & 0.40 & & 0.30 & & 0.40 & & 0.37 & & 0.82 & \\
\hline Autocorrelation coefficient & -0.39 & & -0.36 & & -0.38 & & -0.40 & & -0.36 & & -0.37 & & -0.41 & & -0.29 & \\
\hline $\begin{array}{l}\text { Durbin-Watson statistic } \\
\quad \text { (Original) }\end{array}$ & 2.74 & & 2.70 & & 2.71 & & 2.75 & & 2.69 & & 2.70 & & 2.78 & & 2.53 & \\
\hline $\begin{array}{l}\text { Durbin-Watson statistic } \\
\text { (Transformed) }\end{array}$ & 2.41 & & 2.31 & & 2.40 & & 2.40 & & 2.37 & & 2.37 & & 2.44 & & 2.10 & \\
\hline Observations & 57 & & 57 & & 57 & & 57 & & 57 & & 57 & & 57 & & 57 & \\
\hline
\end{tabular}

Notes: Coef. $=$ Coefficient; $p=p$-value; $p \leq 0.10$ is considered to be significant in this study.

Gasoline prices have both short-term and intermediate-term effects on reducing female drivers' crash rate. In the short term, a $1 \%$ increase in gasoline prices is associated with a $0.31 \%$ decrease in female drivers' monthly total crashes per million VMT. In the intermediate term, a $1 \%$ increase in gasoline prices is associated with a $0.47 \%$ decrease in female drivers' monthly total crashes per million VMT. The crash rate of female drivers is also positively affected by state unemployment.

\subsection{Variations by race}

We also examine variations of gasoline price effects on traffic crashes by whites, blacks, and Latinos. Gasoline prices have both short- term and intermediate-term effects on reducing the crash rate of white drivers. In the short term, a $1 \%$ increase in gasoline prices is associated with a $0.27 \%$ decrease in monthly total crashes per million VMT. In the intermediate term, a $1 \%$ increase in gasoline prices is associated with a $0.44 \%$ decrease in monthly total crashes per million VMT. Traffic crashes of whites are also affected by state unemployment; higher state unemployment is associated with higher crash rates.

For black drivers, gasoline prices also have both short-term and intermediate-term effects on reducing their crash rate. In the short term, a $1 \%$ increase in gasoline prices is associated with a $0.23 \%$ decrease in monthly total crashes per million VMT. In the intermediate term, a 1\% increase in gasoline prices is associated with a $0.55 \%$ decrease in monthly total crashes per million VMT. The crash rate of blacks is also positively affected by state unemployment. Note that the short-term effects are

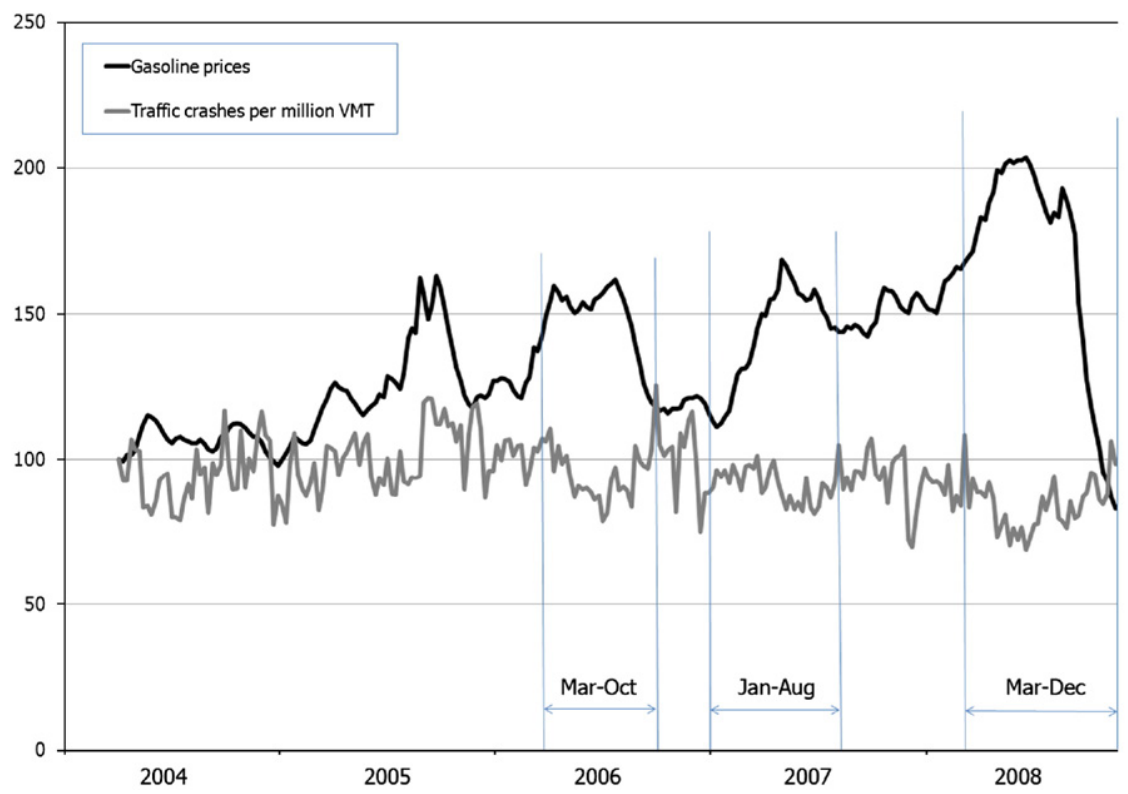

Fig. 3. Gasoline prices and traffic crashes per million VMT in Mississippi, 2004-2008. Note: both gasoline prices and traffic crashes per million VMT are standardized by indices (the first week of April 2004=100). 
Table 4

Elasticities of traffic crashes per million VMT with respect to gasoline prices, April 2004-December 2008, Mississippi.

\begin{tabular}{|c|c|c|c|c|c|c|c|c|}
\hline \multirow[t]{2}{*}{ Gasoline prices } & \multirow[t]{2}{*}{ Total } & \multicolumn{2}{|l|}{ Age } & \multicolumn{2}{|l|}{ Gender } & \multicolumn{3}{|l|}{ Race } \\
\hline & & Younger & Older & Male & Female & White & Black & Latino \\
\hline At current time & -0.2453 & -0.4398 & & & -0.3119 & -0.2726 & -0.2293 & \\
\hline At a 1 -year lag & -0.4692 & & -0.5671 & -0.4707 & -0.4694 & -0.4394 & -0.5504 & \\
\hline \multicolumn{9}{|l|}{ At a 2-year lag } \\
\hline \multicolumn{9}{|l|}{ At a 3-year lag } \\
\hline At a 4-year lag & & & & & & & & -0.8144 \\
\hline
\end{tabular}

stronger on white drivers than black drivers but the intermediate-term effects are stronger on black drivers than white drivers.

For Latino drivers, gasoline prices have long-term effects on reducing crash rates. A $1 \%$ increase in gasoline prices is associated with a $0.81 \%$ decrease in monthly total crashes per million VMT at a 4-year lag. However, caution must be exercised with this interpretation, as Latinos make up a very small proportion of the Mississippi population. Only $2.2 \%$ of the population was of Latino origin in 2008 , which weakens the robustness of the results.

\section{Discussion}

When examining gasoline price effects on traffic safety, previous studies have focused on only fatal crashes rather than total crashes. This study is a step toward filling this gap in the literature because it investigates the effects of gasoline prices on total traffic crashes as well as age, gender, and race variations. The findings of this research provide two policy implications. First, the findings suggest that if decision makers wish to reduce traffic crash rates, increased gasoline taxes are a considerable option because raised gasoline prices reduce traffic crashes directly. While higher gasoline prices due to crude oil price increases are not favored, higher gasoline taxes might be used. Compared to other industrial countries, the United States imposes very low gasoline taxes (only $\$ 0.40$ per gallon of gasoline [federal and state] as of January 2010; Energy Information Administration, 2010). Federal and state taxes accounted for, on average, $25 \%$ of gasoline prices from 2000 to 2006 and only $15 \%$ in 2007 . The additional tax revenues can be used for maintaining or improving transportation infrastructure or other purposes. In addition, gasoline price increases (through taxes) may result in additional societal benefits. Higher gasoline prices will lead to lower gasoline demand and consumption (Bento, Goulder, Jacobsen, \& Von Haefen, 2009), which in turn reduce carbon emissions and slow global warming. Gasoline price increases may also lead to more research and investment in renewable energy production and low-emission or zero-emission vehicles (Niederberger, 2005). These potential benefits should be examined in future research.

Second, transportation policy makers should be prepared for varying effects on traffic safety by age, gender, and race due to possible gasoline price fluctuations. The United States is currently undergoing substantial demographic change: the aging of the baby boomer generation, the rising labor force participation of females, and the increasing Latino population (Himes, 2001; Hughes \& O'Rand, 2004; Riche, 2000). These population cohorts have different socioeconomic characteristics, which lead to variations in driving behaviors, commute modes, and traffic safety. These demographic changes and the consequent demand for changes in transportation need attention from transportation policy makers (Coughlin \& Tompkins, 2009).

There are abundant research opportunities to further study the effects of gasoline prices on traffic safety. First, future research needs to be conducted for other areas, because the findings of this study may not necessarily be transferable to other regions of the United States or other countries. Second, the effects of gasoline prices on traffic safety could be examined at the individual level. Existing studies have focused only on the aggregate level; an analysis at the individual level may provide more insight into the effects from the individual perspective. Third, the data could be further partitioned by levels of income and educational attainment. Partitioning the data might help identify population cohorts whose traffic crash risk is most reduced due to gasoline price increases. Fourth, traffic crash sites could be geocoded and thus researchers could investigate spatial variations of gasoline price effects on traffic safety by employing spatial statistical methods.

\section{Conclusion}

The results suggest that gasoline prices have both short-term and intermediate-term effects on reducing total traffic crashes and crashes of females, whites, and blacks. Gasoline prices also have short-term effects on crashes of younger drivers and intermediate-term effects on crashes of older drivers and male drivers. However, gasoline prices were not found to have long-term effects on reducing crash rates.

Overall, the intermediate-term effects are stronger than the shortterm effects. By age, gasoline price changes produce immediate effects on reducing crashes of younger drivers but longer effects on older drivers. By gender, gasoline prices have short-term effects on reducing crashes of female drivers and intermediate-term effects on reducing crashes of both males and females. By race, gasoline prices have stronger short-term effects on reducing crashes of white drivers than of black drivers, and stronger intermediate-term effects on reducing crashes of black drivers than of white drivers.

\section{Acknowledgements}

The authors would like to thank Neal Feierabend and Lee Weiskopf for deriving traffic crash data, Xuan Zhou for assistance in data analysis and result tabulation, and Timothy E. McClure and Michael Iacono for reviewing earlier drafts of this paper. Appreciation is extended to Bill Ponicki for providing the alcohol consumption data. This research was supported by a grant from Mississippi Office of Highway Safety entitled "Public Safety Data Laboratory" (award number 09K9 401-1). Kim Proctor, Ron Sennett, and Randy Ginn have been very helpful in facilitating this research.

\section{References}

Abdel-Aty, M., \& Radwan, E. (2000). Modeling traffic accident occurrence and involvement. Accident Analysis and Prevention, 32(5), 633-642.

Adams, J. (1995). Risk. London: Routledge.

Arnett, J. J. (2002). Developmental sources of crash risk in young drivers. Injury Prevention, 8(Suppl. II), ii17-ii23.

Beer Institute. (2009). Annual Statistical Abstracts of Brewers Almanac, 2009. Available at. http://www.beerinstitute.org/statistics.asp?bid=200 Access date: January 12, 2009.

Bento, A. M., Goulder, L. H., Jacobsen, M. R., \& Von Haefen, R. H. (2009). Distributional and efficiency impacts of increased US gasoline taxes. The American Economic Review, 99, 667-699.

Carruth, A. A., Hooker, M. A., \& Oswald, A. J. (1998). Unemployment equilibria and input prices: Theory and evidence from the United States. The Review of Economics and Statistics, 80, 621-628.

Coughlin, J. F., \& Tompkins, C. J. (2009). Demographics, destiny, and anticipating the future of the transportation system. Public Works Management and Policy, 13, $284-287$.

Dahl, C. A., \& Sterner, T. (1991). Analyzing gasoline demand elasticities: A survey. Energy Economics, 13(3), 203-210. 
Dickey, D. A. \& Fuller, W. A. (1979). Distribution of the estimators for autoregressive time series with a unit root. Journal of the American Statistical Association, 74, 427-431.

Durbin, J., \& Winsten, G. S. (1950). Testing for serial correlation in least-squares regression. Biometrika, 37, 409-428.

Durbin, J., \& Winsten, G. S. (1951). Testing for serial correlation in least-squares regression. Biometrika, 38, 159-178.

Edwards, M. (2001). Standards for novice driver education and licensing. Driver Education at the Crossroads. Proceedings from the Committee on Operator Education and Regulation (Report No. E-C024), Transportation Research Circular. Washington, DC: Transportation Research Board.

Energy Information Administration. (2010). Federal and State Motor Fuels Taxes (Table EN1), Petroleum Marketing Monthly June 2010. Available at. http://www. eia.doe.gov/pub/oil_gas/petroleum/data_publications/petroleum_marketing monthly/current/pdf/enote.pdf Access date: June 7, 2010.

Grabowski, D. C., \& Morrisey, M. A. (2004). Gasoline prices and motor vehicle fatalities. Journal of Policy Analysis and Management, 23, 575-593.

Grabowski, D. C., \& Morrisey, M. A. (2006). Do higher gasoline taxes save lives? Economic Letters, 90, 51-55.

Graham, D. J., \& Glaister, S. (2003). Spatial variation in road pedestrian casualties: The role of urban scale, density and land-use mix. Urban Studies, 40(8), 1591-1607.

Hilton, J. (2006). Race and Ethnicity: Factors in Fatal Motor Vehicle Traffic Crashes 19992004. Washington, DC: U.S. National Highway Traffic Safety Administration.

Himes, C. L. (2001). Elderly Americans. Population Bulletin, 56(4), 1-40.

Hughes, M. E., \& O'Rand, A. M. (2004). The Lives and Times of the Baby Boomers. Washington, DC: Population Reference Bureau.

Karlis, D. (2006). Time series model for count data. Paper presented at the annual conference of the Transportation Research Board, Washington, DC. .

Kenkel, D. S. (1993). Drinking, driving, and deterrence: The effectiveness and socia costs of alternative policies. Journal of Law and Economics, 36(2), 877-913.

Kulmala, R. (1995). Safety at Rural Three-and Four-arm Junctions: Development and Application of Accident Prediction Models. Technical Research Center at Espoo. Finland: VTT Publications.

Leigh, J. P., \& Geraghty, E. M. (2008). High gasoline prices and mortality from motor vehicle crashes and air pollution. Journal of Occupational and Environmental Medicine, 50, 249-254.

Leigh, J. P., \& Wilkinson, J. T. (1991). The effect of gasoline taxes on highway fatalities. Journal of Policy Analysis and Management, 10, 474-481.

Lord, D. (2000). The Prediction of Accidents on Digital Networks: Characteristics and Issues Related to the Application of Accident Prediction Models. Ph.D. Dissertation, Department of Civil Engineering, University of Toronto, Toronto.

Mayhew, D. R., Ferguson, S. A., Desmond, K. J., \& Simpson, H. M. (2003). Trends in fatal crashes involving female drivers, 1975-1998. Accident Analysis and Prevention, 35 (3), 407-415.

McGwin, G., \& Brown, D. B. (1999). Characteristics of traffic crashes among young middle-aged, and older drivers. Accident Analysis and Prevention, 31, 181-198.

Miaou, S. P. (1994). The relationship between truck accidents and geometric design of road sections: Poisson versus negative binomial regressions. Accident Analysis and Prevention, 26(4), 471-482.

National Highway Traffic Safety Administration [NHTSA]. (2009). Fatality Analysis Report System Encyclopedia. Available at. http://www-fars.nhtsa.dot.gov/Main/ index.aspx Access date: April 5, 2009.

Niederberger, A. A. (2005). The Swiss Climate Penny: An innovative approach to transport sector emissions. Transport Policy, 12, 303-313.

Peltzman, S. (2004). Regulation and the Natural Progress of Opulence. Paper presented at the American Enterprise Institute. September 8, 2004. Available at. Washington, D.C: AEI-Brookings Joint Center for Regulatory Studieshttp://aei-brookings.org/admin/ authorpdfs/redirect-safely.php?fname $=. . /$ pdffiles/phpUS.pdf Access date: October 6, 2009.

Prais, S. J., \& Winsten, C. B. (1954). Trend Estimators and Serial Correlation. Cowless Commission Discussion Paper No. 383, Chicago, IL.
Quddus, M. A. (2008a). Modelling area-wide count outcomes with spatial correlation and heterogeneity: An analysis of London crash data. Accident Analysis and Prevention, 40(4), 1486-1497.

Quddus, M. A. (2008b). Time-series count data models: an empirical application to traffic accidents. Accident Analysis and Prevention, 40(5), 1732-1741.

Riche, M. F. (2000). American's diversity and growth: Signposts for the 21st century. Population Bulletin, 55(2), 1-43.

Thomas, K. (2009). US Highway Deaths at Lowest Levels since 1961. Available at Associated Press http://www.saferoads.org/us-highway-deaths-lowest-levels1961 Access date: January 6, 2009.

U.S. Bureau of Labor Statistics. (2009). Local Area Unemployment Statistics. Available at. http://data.bls.gov/PDQ/servlet/SurveyOutputServlet?data_tool=latest_numbers\&series_id=LASST28000003 Access date: June 24, 2009.

Voas, R. B., Romano, E., \& Peck, R. (2009). Validity of surrogate measures of alcohol involvement when applied to nonfatal crashes. Accident Analysis and Prevention, 41 $522-530$.

Williams, A. F. (2003). Teenage drivers: Patterns of risk. Journal of Safety Research, 34, 5-15.

Williams, A. F., Preusser, D. F., \& Ferguson, S. A. (1998). Fatal crashes involving 16-yearold drivers: Narrative descriptions. Journal of Traffic Medicine, 26, 11-17.

Williams, J. M., (2008). Oil Price History and Analysis. Available at http://www.wtrg. com/prices.htm. Access date: July 24, 2009.

Wilson, F. A., Stimpson, J. P., \& Hilsenrath, P. E. (2009). Gasoline prices and their relationship to rising motorcycle fatalities, 1990-2007. American Journal of Public Health, 99, 1753-1758.

Guangqing Chi is an Assistant Professor of Sociology and Research Fellow of the Social Science Research Center at Mississippi State University, USA. He is a demographer and sociologist skilled in spatial analysis. His work is focused on the social and spatial aspects of transportation infrastructure. He has a Ph.D. in Environmental Demography from University of Wisconsin-Madison and a M.S. in Environmental Policy from Michigan Technological University.

Arthur G. Cosby is William L. Giles Professor and Director of the Social Science Research Center at Mississippi State University, USA. His research applies social science knowledge to such real-world problems as health, poverty, career development, racial disparities, tobacco control, families/children, and policy studies. He has a Ph.D. and a M.A. in Sociology from Mississippi State University.

Mohammed A. Quddus is a Senior Lecturer in Transport Studies at Loughborough University, UK. His main research interests are in road transport safety, geographic information science and its application to transport planning. He has a Ph.D. and a M.S in Civil Engineering from Imperial College London and National University of Singapore, separately.

Paul A. Gilbert is a Ph.D. student in sociology at Mississippi State University, USA. His research interests are in transportation effects on minorities and low-income groups. He has a M.A. in Sociology from Brown University.

David Levinson is Richard P. Braun/CTS Chair in Transportation Engineering and Director of the Networks, Economics, and Urban Systems at the University of Minnesota, USA. He is an associate professor in the Department of Civil Engineering at the University of Minnesota. His research focuses on transportation policy, planning and deployment, transportation and land use interactions, traffic safety, and travel behaviors. He has a Ph.D. and a M.S. in Civil Engineering from University of California, Berkeley. 